\title{
CORRESPONDENCE
}

\section{Amateurs as an outreach of HAARP's lunar-echo study}

SIR - Your News Feature

'Heating up the heavens'

(Nature 452, 930-932; 2008)

discusses experiments using the

High Frequency Active Auroral

Research Program (HAARP)

facility. I would like to clarify

the goal of the lunar-echo

experiments.

The high power and low-

frequency range of HAARP

provide radio waves that can penetrate the lunar surface because of the low electrical conductivity of the lunar regolith, allowing investigation of the subsurface. Parallel research efforts currently use radar sounders on satellites orbiting the Moon. In its radar mode, HAARP is the most powerful of the few Earth-based facilities that can participate in such investigations.

Our lunar-echo experiments began in 2001, when HAARP was not yet at full power capability, but in the latest experiment we succeeded in receiving a lunar echo at the lowest frequency obtained so far by an Earth-based radar (4.8 megahertz). Our initial results will be presented at the General Assembly of the International Union of Radio Science in August 2008.

The fact that radio amateurs can record the HAARP transmissions and lunar echoes is a result of free-space propagation of the radio waves. In the lunar-echo experiment of January 2008 that you mention, the schedule of the HAARP transmissions was provided so that they could listen in during the research activities. That opportunity was enthusiastically and successfully taken up by radio amateurs in many countries and has produced interesting data in its own right, related to worldwide propagation effects on the two-way (Earth-Moon-Earth) radio signals - for example, on ionospheric refraction, scattering and scintillation.

Paul Rodriguez ITT Corporation Consultant, Code 5550, Naval Research Laboratory, Washington DC 20375, USA

\section{Reality lags behind rhetoric in building interdisciplinary work}

SIR - As a PhD student in archaeology and genetics, I am all too aware of the difficulties in crossing a gaping discipline divide, as well as of their effect on academic career prospects, as discussed in the Naturejobs article 'Assembly work' (Nature 453, 422-423; 2008).

For my master's degree in biomolecular archaeology, I needed a foot in two UK universities: one in the University of Manchester's biology department and the other in the University of Sheffield's archaeology department. My former lecturers later became part of the Manchester Interdisciplinary Biocentre (MIB) and the MSc course shifted to Sheffield, where eventually the programme ceased.

This closure was a disappointment for the nascent field of bioarchaeology, set to thrive only on a foundation of solid postgraduate training. Although the MIB and other new centres for interdisciplinary research are enthusiastically welcomed, they are few and far between and so able to offer only limited postdoctoral prospects.

Opening such centres and creating training programmes is not enough - it is also necessary to make interdisciplinary fields attractive to graduates and for senior academics to appreciate their significance. This would improve project turnover, bringing more funding to collaborative projects that would sustain interdisciplinary centres and allow academics from each discipline to gauge publications on an equal footing.

Perhaps then my search for a postdoctoral position in bioarchaeology would be easier. Although interdisciplinary projects are viewed as hot topics, in reality they lag behind as they await official establishment and recognition.

Danae Rebecca Dodge Graduate

School of Archaeology, West Court, 2 Mappin Street, University of Sheffield, Sheffield S1 4DT, UK

\section{Reduce confusion by using 'design' more intelligently}

SIR - Few scientists would dispute that evolution provides a far more satisfactory explanation for the workings of living organisms than does 'intelligent design'. But a much more subtle 'design' movement abounds that can distort how they approach their research.

According to the Oxford English Dictionary, the noun 'design' means "the thing aimed at; the end in view; the final purpose". Biologists frequently use 'design' to describe the organization of components in a system - for instance, in a network of signalling molecules, a cell's cytoskeleton, or a protein's domain structure. Readers need look no further than articles in scientific publications and their podcasts for other examples.

It would be easy to dismiss criticism of this as mere pedantry, if it weren't for puzzled researchers voicing concern at the seemingly illogical or counterintuitive 'design' of a biological structure or process. They fail to note that its construction is a consequence of the incremental, biased random walk of evolution, and this can affect their choice of approach in tackling the problem.

Systems that emerge by selection differ fundamentally from those conceived by design.
Failing to acknowledge this in our choice of words is lazy, clutters our thinking and does a disservice to those entering biology from disciplines (scientific and nonscientific) in which evolution by selection is not a central theme and the word 'design' carries inherent baggage.

Richard Sever Cold Spring Harbor Laboratory, 1 Bungtown Road, Cold Spring Harbor, New York 11724, USA

\section{Picture not quite worth 1,000 words in this case}

SIR - In your News story 'Top billing for platypus at end of evolution tree' (Nature 453, 138-139; 2008), the graphic depicting genome status presents a shocking new phylogeny of the Vertebrates - with Archosaurs (birds and crocodilians) and Mammals forming a monophyletic group.

The bad news is that this dramatic new 'proposal' is completely adrift from the research Article by Wesley C. Warren and colleagues that the figurative tree is intended to illustrate (Nature 453, 175-183; 2008), and it continues a persistent tendency in popular literature to portray all evolution as leading towards humans.

The good news is that figures 1 and 4 in the original Article both correctly show the properly supported phylogeny that holds the Archosaurs as sister group to the Turtle + Diapsid clade. Even better news is that a news story that appeared in Science the following day (Science 320,$730 ; 2008$ ) about the platypus research also showed a cladogram containing essentially the same error. One wonders whether the similarity in errors between the two news stories is an example of homology or homoplasy.

\section{Peter K. Ducey Department of} Biological Sciences, State University of New York at Cortland, Cortland, New York 13045, USA 